\title{
Effect of mechanical activation on cordierite synthesis through solid-state sintering method
}

\author{
S K NATH*, SANJAY KUMAR and RAKESH KUMAR \\ CSIR-National Metallurgical Laboratory, Jamshedpur 831 007, India
}

MS received 14 March 2013; revised 28 August 2013

\begin{abstract}
Synthesis of cordierite $\left(5 \mathrm{SiO}_{2} \cdot 2 \mathrm{MgO} \cdot 2 \mathrm{Al}_{2} \mathrm{O}_{3}\right)$ has attracted special attention from researchers for its special characteristics. Most common method of cordierite preparation is solid-state reaction using source of alumina, silica and magnesia, which requires temperature of $1350{ }^{\circ} \mathrm{C}$ or above. This study deals with the effect of mechanical activation on cordierite synthesis at lower temperature. Talc, kaolinite clay and alumina powder were taken as precursor materials and the batches were formulated on the basis of stoichometric cordierite formation. Particle size distribution (PSD) was measured to get the distribution pattern of milled powder. Pellets were prepared by compaction of dried milled powders and fired at $1200{ }^{\circ} \mathrm{C}$ temperature. $\mathrm{X}$-ray diffraction (XRD) technique was used to characterize crystalline phases. Microstructural analysis was done under scanning electron microscope (SEM). It was observed that properties were improved with milling time. Dense and uniform microstructures were formed when samples were milled for $\mathbf{4 5}$ and 60 min.
\end{abstract}

Keywords. Cordierite; attrition milling; mechanical activation; sintering; microstructure.

\section{Introduction}

Cordierite is an important ceramic material due to its low coefficient of thermal expansion $\left(\sim 2 \times 10^{-6}{ }^{\circ} \mathrm{C}^{-1}\right)$, good thermal shock resistance, high refractoriness, low dielectric constant and high resistivity, which has application in some special areas like kiln furniture, catalytic converters, filters and refractory materials (Gokce et al 2011). Cordierite, $5 \mathrm{SiO}_{2} \cdot 2 \mathrm{MgO} \cdot 2 \mathrm{Al}_{2} \mathrm{O}_{3}$, is one of the important phases of the $\mathrm{MgO}-\mathrm{SiO}_{2}-\mathrm{Al}_{2} \mathrm{O}_{3}$ ternary system. It is a naturally occurring material, but its availability in nature is very poor; thus, research on artificial or synthetic cordierite has got special attention. As cordierite is a magnesium alumino-silicate mineral, it can be synthesized by using source of magnesia, alumina and silica. The solid-state method by reaction sintering is the most common method for cordierite preparation (Kumar et al 2000; Ghitulica et al 2007). The other reported methods of cordierite preparation are co-precipitation (Awano et al 1992), sol-gel (Bertran et al 2000; Menchi and Scian 2005), combustion synthesis (Ianos et al 2009), etc. The temperature required for cordierite formation through solid-state reaction is $\sim 1400{ }^{\circ} \mathrm{C}$ (Gonzalez-Velasco et al 2005). Whereas $1300{ }^{\circ} \mathrm{C}$ temperature is required for full conversion of cordierite through sol-gel method (Menchi and Scian 2005).

The reactivity of solids at high temperature is strongly influenced by the starting material and process parameters.

*Author for correspondence (nathsusanta@gmail.com)
Mechanochemistry is the branch of science dealing with intentional formation of defects in the structure of solids by application of mechanical forces, normally by intensive grinding or milling (Kumar and Kumar 2011). The mechanical treatment of starting materials is important as it can help to change the structure and texture of solids, causing reduction of particle size and lowering the sintering temperature (Zhang et al 2004; Cristobal et al 2011). The defects induced during mechanical activation into solid states is characterized by non-equilibrium conditions and termed as meta-stable or active state (Boldyrev 1987). These states can be explained by the following thermodynamic reaction between activated and equilibrium states (Tkacova et al 1993)

$$
\begin{aligned}
\Delta G_{\mathrm{T}}= & G_{\mathrm{T}}^{*}-G_{\mathrm{T}}=\left(H_{\mathrm{T}}^{*}-H_{\mathrm{T}}\right) \\
& -T\left(S_{\mathrm{T}}^{*}-S_{\mathrm{T}}\right) \stackrel{\text { At room temperature }}{\longrightarrow} \Delta G_{\mathrm{T}} \approx H_{\mathrm{T}} .
\end{aligned}
$$

where $G_{\mathrm{T}}, H_{\mathrm{T}}$ and $S_{\mathrm{T}}$ are the free energy, enthalpy and entropy, respectively, in equilibrium states and $G_{\mathrm{T}}^{*}, H_{\mathrm{T}}^{*}$ and $S_{\mathrm{T}}^{*}$ are the free energy, enthalpy and entropy, respectively, in the activated state.

The effect of intensive grinding of precursor materials during formation of compounds like mullite (Temuujin et al 1998), spinel (Marinkovic Stanojevic et al 2007) and cordierite (Tamborenea et al 2004; Yalamac and Akkurt 2006) has been reported. During mechanical activation precursors, materials lose their crystallinity and, thus, improve their reactivity (Tamborena et al 2004). The 
Table 1. Chemical composition and physical properties of raw materials.

\begin{tabular}{lccc}
\hline & Kaolinite clay & Talc & Alumina \\
\hline Chemical constituents (\%) & & & \\
$\mathrm{SiO}_{2}$ & $54 \cdot 02$ & $60 \cdot 54$ & - \\
$\mathrm{Al}_{2} \mathrm{O}_{3}$ & $33 \cdot 63$ & $0 \cdot 14$ & $99 \cdot 50$ \\
$\mathrm{Fe}_{2} \mathrm{O}_{3}$ & $2 \cdot 01$ & $0 \cdot 80$ & $0 \cdot 03$ \\
$\mathrm{CaO}$ & $0 \cdot 10$ & $1 \cdot 50$ & $0 \cdot 05$ \\
$\mathrm{MgO}$ & $1 \cdot 39$ & $32 \cdot 07$ & - \\
$\mathrm{Na} \mathrm{O}_{2} \mathrm{O}$ & $0 \cdot 01$ & $0 \cdot 16$ & $0 \cdot 30$ \\
$\mathrm{~K} \mathrm{O}$ & $1 \cdot 21$ & $0 \cdot 04$ & - \\
$\mathrm{LOI}$ & $5 \cdot 24$ & $5 \cdot 17$ & $0 \cdot 10$ \\
& & & \\
Physical properties & & & $3 \cdot 62$ \\
Apparent sp. gravity & $1 \cdot 97$ & $2 \cdot 71$ & $4 \cdot 34$ \\
$D_{50}(\mu$ m) & $7 \cdot 81$ & $10 \cdot 73$ & $\alpha$-alumina \\
Major phases & Kaolinite and quartz & Talc & \\
\end{tabular}

effect of intensive grinding along with additive and without additive on cordierite sintering has been studied by several researchers (Yalamac and Akkurt 2006; Obradovic et al 2012).

In this study, the influence of mechanical activation on the synthesis of cordierite through solid-state reaction has been studied. The milling effects on cordierite formation have been studied with different milling times. The texture and properties of cordierite bodies were changed with milling time. Milling effects of different durations on cordierite synthesis have been studied in terms of cordierite phase conversion, compact microstructure development and evolution of physical properties. The properties of milled samples were measured and compared with unmilled reference sample. Finally, an attempt has been made to correlate the milling effects on sintering and the final properties of cordierite.

\section{Experimental}

\subsection{Raw materials characterization}

The raw materials used in this study were talc, kaolinite clay and alumina powder. Talc and kaolinite clay were supplied by LOBA Chemie Pvt. Ltd., India, and alumina was procured from Alcoa, India. Chemical compositions and physical properties of the raw materials are illustrated in table 1. Particle size distribution (PSD) of raw materials was measured by laser particle size analyser, Mastersizer 2000, Malvern. The PSD graphs of all the three raw materials are presented in figure 1.

Phase analysis of the raw materials was carried out in Bruker, Model-D8 Discover, X-ray diffractometer by using an Ni filter with $\mathrm{CuK} \alpha$ radiation. The major identified phases are listed in table 1. Microstructural analysis was performed using Hitachi scanning electron microscope (SEM), model: S-3400N.

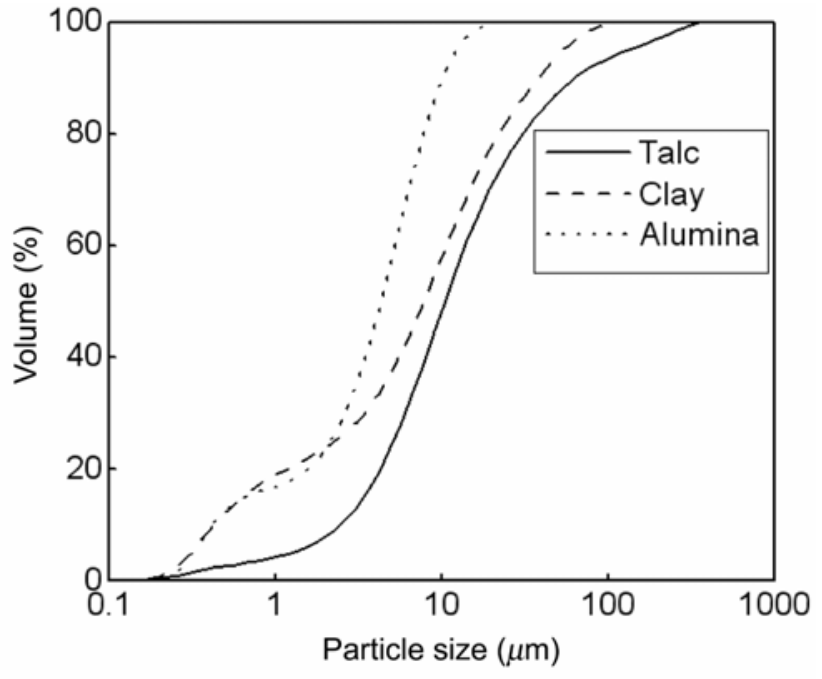

Figure 1. PSD graph of raw materials.

\subsection{Attrition milling and sample preparation}

Talc, kaolinite clay and alumina powder were weighed in such a mole ratio that the stoichometric cordierite $\left(2 \mathrm{MgO} \cdot 2 \mathrm{Al}_{2} \mathrm{O}_{3} \cdot 5 \mathrm{SiO}_{2}\right)$ was formed according to the following reaction

$$
\begin{gathered}
4\left[\mathrm{Mg}_{3} \mathrm{Si}_{4} \mathrm{O}_{10}(\mathrm{OH})_{2}\right]+7\left[\mathrm{Al}_{2} \mathrm{Si}_{2} \mathrm{O}_{5}(\mathrm{OH})_{4}\right]+5 \mathrm{Al}_{2} \mathrm{O}_{3} \\
\rightarrow 6\left[\mathrm{Mg}_{2} \mathrm{Al}_{4} \mathrm{Si}_{5} \mathrm{O}_{18}\right]+18 \mathrm{H}_{2} \mathrm{O} .
\end{gathered}
$$

The mixture was loaded into an attrition mill (model: PE-075), NETZSCH (Germany), using $2 \mathrm{~mm}$ steel ball in wet condition. Four different batches were produced with milling time of 15, 30, 45 and 60 min with a fixed stirring speed of $1000 \mathrm{rpm}$. After milling, the slurry was collected and kept in the drier. The dried cakes were crushed into powder shape and passed through 100 no. BS sieve (particle size is equivalent to $149 \mu \mathrm{m}$ ). Batch details are presented in table 2 . 


\subsection{Milling powder characterization}

The PSD graphs of all the milled batches were determined. The differential thermal analysis (DTA) and thermogravimetric (TG) analysis were carried out after milling of all batches with SEIKO equipment using platinum crucible with $\alpha$-alumina as reference and with a heating rate of $10{ }^{\circ} \mathrm{C}$ per minute up to $1200{ }^{\circ} \mathrm{C}$ temperature.

\subsection{Preparation of samples}

The sieved powder was pressed in a hydraulic press to make pellets at a pressure of $100 \mathrm{MPa}$. The pressed samples were subjected to drying at $110{ }^{\circ} \mathrm{C}$ to remove moisture in an air oven. After drying, the samples were fired at $1200{ }^{\circ} \mathrm{C}$ with $2 \mathrm{~h}$ soaking time. To compare the milling effect, one reference sample was made by mixing of unmilled talc, kaolinite clay and alumina in appropriate proportions. This sample was marked as KAT00.

\subsection{Evolution of properties and characterization}

Physical properties like apparent porosity (AP \%), water absorption (WA \%) and bulk density (BD) were measured for all the fired samples by boiling, following Archimedes principle. The crystalline phases were identified by XRD technique. The microstructures of fractured surface of sintered body were observed under SEM.

\section{Results and discussion}

\subsection{Characterization of raw materials}

Kaolinite clay is the aluminum silicate material with a small percentage of impurities like iron oxide, magnesium oxide, potassium oxide, etc. Kaolinite clay provides the alumina and silica into cordierite composition. Talc is magnesium silicate with a very small percentage of impurities and it provides the necessary requirements of magnesia and balances the deficiency of silica. Kaolinite clay does not fulfill the required amount of alumina for stoichometric cordierite formation. Hence, to balance the alumina amount, pure alumina powder is added to the composition. Particle size distribution of the three raw materials is shown in figure 1 . Alumina is finer than the other two raw materials, and shows the short-range order of distribution. Talc is coarser and has a long-range particle size distribution order. The XRD analysis confirms that talc and $\alpha$-alumina are the major crystalline phase of talc and alumina, respectively. Kaolinite clay has two major phases, namely, kaolinite and quartz.

\subsection{Characterization of milled batches}

Effect of milling on particle size distribution of all batches is presented in figure 2. A variation of selected cut point particle size values with different milling time is shown in table 2. As expected, attrition milling not only decreases the particle size, but also increases the volume of finer particles. The size reduction is prominent up to 15 min milling, and size distribution significantly shifts to finer sizes, see figure 2. Milling efficiency in terms of size reduction is gradually increased with milling time. The milling efficiency also depends on particle size of starting materials, hardness, material to milling media ratio, etc. To obtain a comparison, here, all other

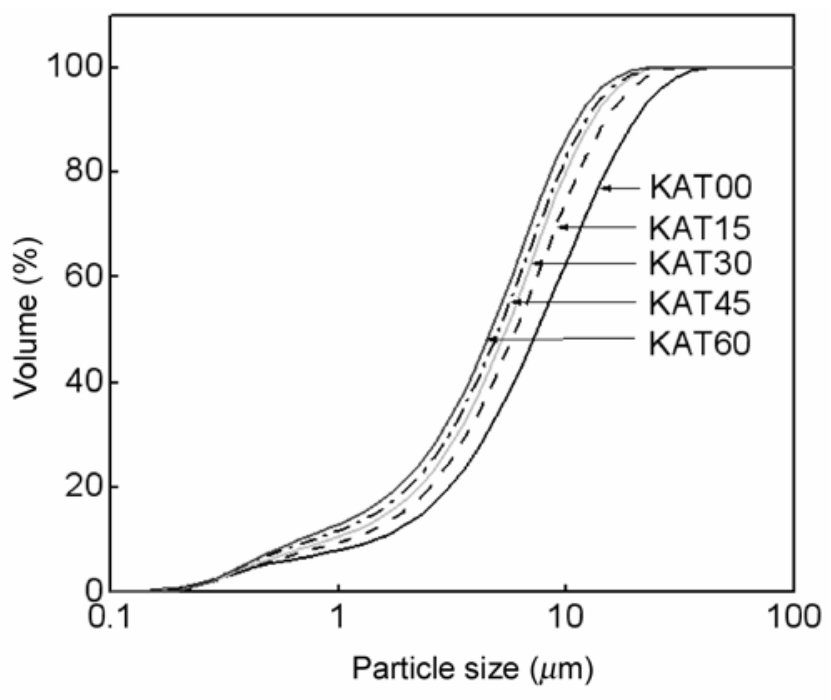

Figure 2. PSD graphs of raw batches.

Table 2. Batch details.

\begin{tabular}{|c|c|c|c|c|c|c|}
\hline \multirow[b]{2}{*}{ Batch ID } & \multirow[b]{2}{*}{ Raw materials } & \multirow[b]{2}{*}{ Milling time (min) } & \multicolumn{3}{|c|}{ Particle size $(\mu \mathrm{m})$} & \multirow[b]{2}{*}{ Firing temp. $\left({ }^{\circ} \mathrm{C}\right)$} \\
\hline & & & $D_{10}$ & $D_{50}$ & $D_{90}$ & \\
\hline КАТ00 & Kaolinite clay, alumina, talc & 0 & 1.44 & $7 \cdot 48$ & $20 \cdot 00$ & 1200 \\
\hline KAT15 & DO & 15 & 1.09 & $6 \cdot 02$ & 14.92 & 1200 \\
\hline КАТЗ0 & DO & 30 & $0 \cdot 91$ & 5.43 & $12 \cdot 96$ & 1200 \\
\hline KAT45 & DO & 45 & 0.77 & $5 \cdot 07$ & $12 \cdot 17$ & 1200 \\
\hline KAT60 & DO & 60 & 0.67 & $4 \cdot 68$ & $11 \cdot 10$ & 1200 \\
\hline
\end{tabular}

$D_{10}$, less than 10 volume\%; $D_{50}$, less than 50 volume\% and $D_{90}$, less than 90 volume $\%$ particles under mentioned size. 
parameters were kept constant, and a similar pattern of PSD observed (figure 2).

\subsection{Characterization of thermal behaviour of milled batches}

Differential thermal and thermogravimetric analyses were performed to see the milling effect on thermal behaviour of cordierite batches and the results are shown in figure 3(a) and (b), respectively. Figure 3(a) and (b) compare the thermal behaviour of unmilled (KAT00) with those of milled batches. All TG curves are very similar, exhibiting three weight loss steps. Two important weight loss steps are between room temperature to $150{ }^{\circ} \mathrm{C}$ and between 500 and $900{ }^{\circ} \mathrm{C}$. The first weight loss is due to the presence of physically bonded water and the amount of which increases with the release of adsorbed water of an enhanced surface area after milling. This weight loss is accompanied with a weak endothermic effect in the DTA
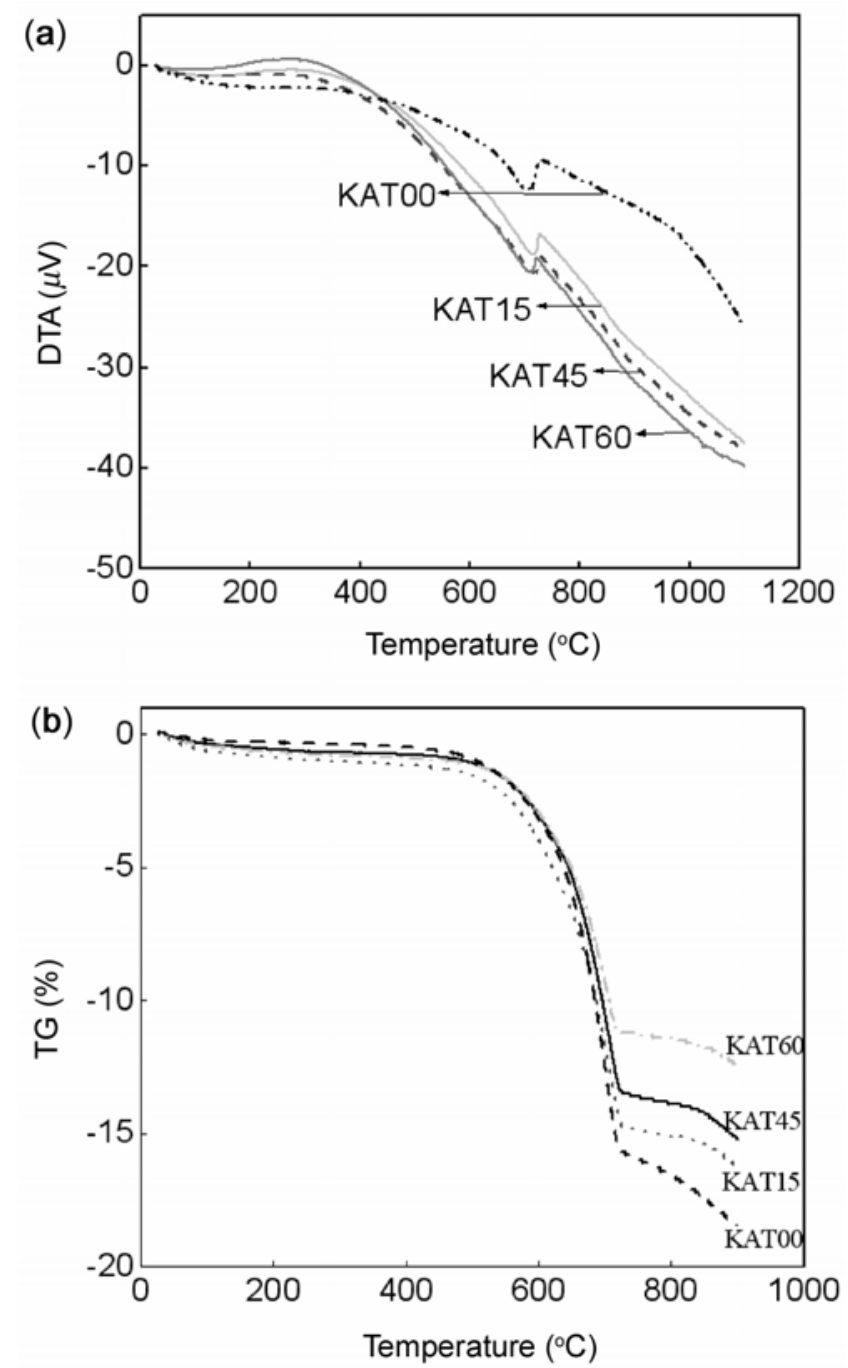

Figure 3. (a) DTA and (b) TG graphs of raw batches. curve, figure 3(a). The weight loss starts at around $500{ }^{\circ} \mathrm{C}$ and ends at around $900{ }^{\circ} \mathrm{C}$ due to the de-hydroxylation of kaolinite clay and talc in the mixture. The same is indicated in the DTA diagram of figure 3(a), with an endothermic peak centred at $750{ }^{\circ} \mathrm{C}$. This kind of nature is due to the combined effect of raw materials, as the thermal behaviour of clay mineral such as talc and clay is different. These observations revealed that milling significantly modifies the thermal behaviour of starting materials during cordierite formation.

\subsection{Characterization of cordierite}

Physical properties such as AP \%, BD and WA \% are shown in table 3 . The physical properties were improved with an increase in milling time. This improvement in physical properties is quite significant between 30 and $45 \mathrm{~min}$ of milling, whereas beyond $45 \mathrm{~min}$, improvement is negligible. This can be attributed to the modification and reorganization of the structure during milling. This in turn influences the sintering temperature of cordierite formation. XRD graphs of the selected milled samples and the reference sample are shown in figure 4. The PDF number of the identified phases is given in table 4 . It is

Table 3. Physical properties of the fired samples.

\begin{tabular}{lccc}
\hline Sample name & BD (g/cc) & AP (\%) & Water absorption (\%) \\
\hline KAT00 & $1 \cdot 77$ & $26 \cdot 37$ & $22 \cdot 30$ \\
KAT15 & $1 \cdot 82$ & $24 \cdot 50$ & $21 \cdot 00$ \\
KAT30 & $2 \cdot 10$ & $20 \cdot 30$ & $17 \cdot 20$ \\
KAT45 & $2 \cdot 26$ & $12 \cdot 40$ & $2 \cdot 00$ \\
KAT60 & $2 \cdot 45$ & $8 \cdot 20$ & $1 \cdot 70$ \\
\hline
\end{tabular}

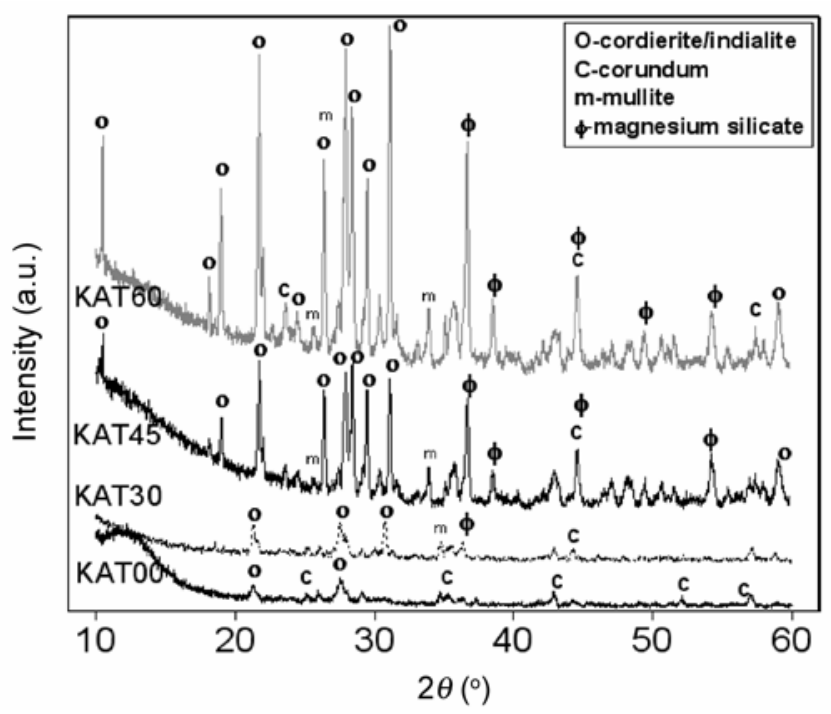

Figure 4. XRD graphs of the fired samples. 
Table 4. Identified phases and their corresponding PDF numbers of fired samples.

\begin{tabular}{lc}
\hline Phase name & PDF no. \\
\hline Cordierite & $13-0294,89-1485$ \\
Indialite & $12-0245,48-1600$ \\
Mullite & $15-0776,10-0394$ \\
Syn. magnesium aluminum silicate & $83-2203$ \\
Magnesium silicate & $88-1927$ \\
Corundum & $75-0783,77-2135$ \\
\hline
\end{tabular}

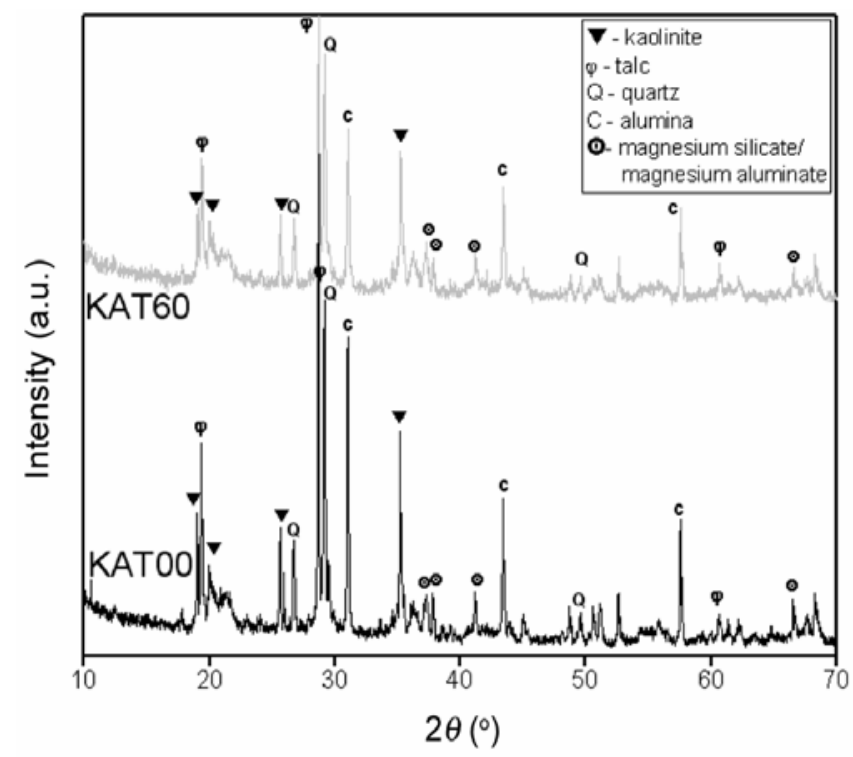

Figure 5. XRD graphs of raw mixes.

Table 5. Identified phases and their corresponding PDF numbers of raw mixes.

\begin{tabular}{ll}
\hline Phase name & PDF no. \\
\hline Kaolinite & $83-0971$ \\
Talc & $83-1768$ \\
Quartz & $88-2487$ \\
Alumina & $86-1410$ \\
Magnesium silicate & $87-2034$ \\
Magnesium aluminate & $87-0343$ \\
\hline
\end{tabular}

observed that with increase in the milling time, the number of crystalline peaks as well as the peak intensity increase. The major crystalline peaks of KAT60 sample are identified as cordierite and indialite. Mullite, $\mathrm{MgSiO}_{3}$ and corundum peaks are also detected by XRD. Mullite is formed due to the presence of clay, and formation of $\mathrm{MgSiO}_{3}$ is due to decomposition of talc and alumina. Cordierite peaks are prominent in KAT45 and KAT60 samples (figure 4). Few cordierite peaks are obtained in KAT30 sample, whereas no such crystalline peak is observed in the KAT00 sample. XRD analysis of raw mixtures before and after milling is carried out to know the phases present in mixes before sintering (figure 5).
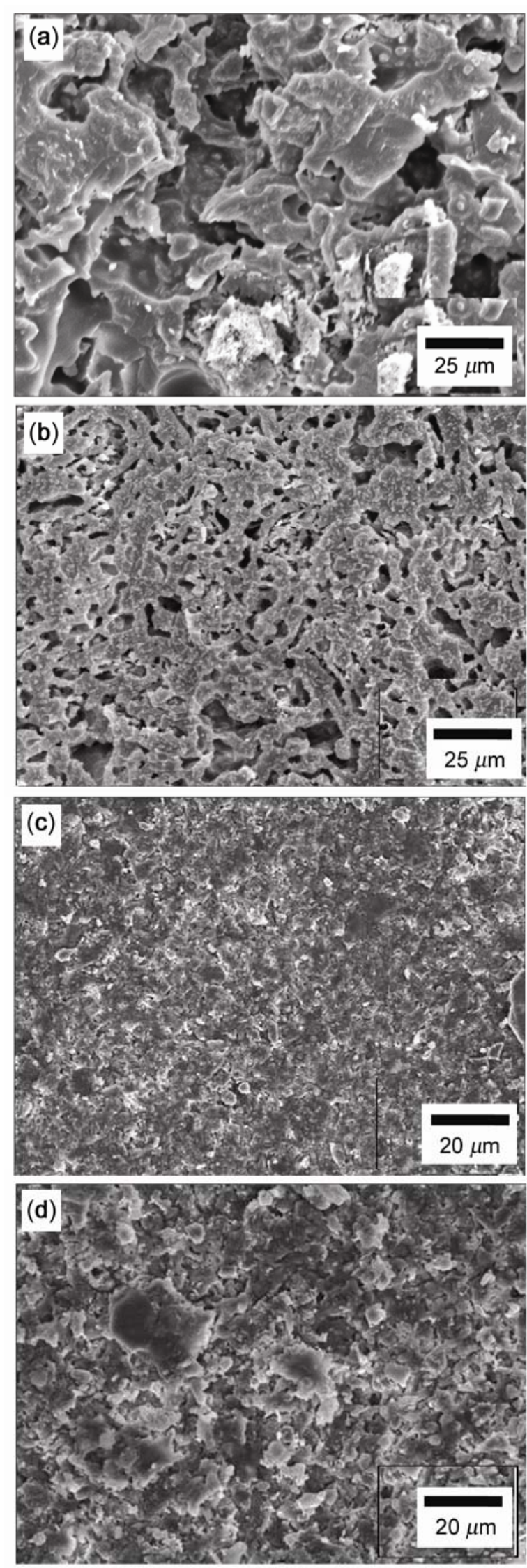

Figure 6. SEM micrographs of (a) KAT00, (b) KAT30, (c) KAT45 and (d) KAT60. 
The main identified phases are kaolinite, talc, quartz, alumina, magnesium silicate and magnesium aluminate. The corresponding PDF numbers of the identified phases are presented in table 5 . The peak intensity is higher in the KAT00 sample compared to the KAT60 sample (figure 5). This is due to grain refinement by mechanical activation. So, it can be concluded that the cordierite is formed during the process of sintering, and XRD study gives a clear indication of the milling effect on formation of crystalline phases through solid-state reaction. It is found that mechanical activation helps in conversion of cordierite at relatively lower $\left(1200^{\circ} \mathrm{C}\right)$ temperature. The microstructures of a fractured surface of selected sintered samples are presented in figure 6(a)-(d). Compact microstructure and refinement of grains are observed in KAT45 and KAT60 samples. In comparison with KAT45 and KAT60, less compactness and more porosity are observed in KAT30 and KAT00 samples. Milling helped to build up compact and dense microstructure. These results are supported by the physical properties such as apparent porosity and bulk density. Most dense microstructure and uniform grains are found in KAT60 sample, whereas KAT00 and KAT30 samples are featured with porosities and larger grains. By observing the microstructures of the sintered body, it can be concluded that mechanical activation helps in develop a uniform microstructure with less porosity.

Mechanical activation increases the specific surface area by decreasing the particle size and resulting in an increase of the active surface. These activated particles can participate in the reactions of the cordierite conversion. After mechanical activation, the reaction kinetics may significantly change in terms of their acceleration, which leads to significant improvements in the properties.

\section{Conclusions}

With the help of mechanical activation, cordierite can be synthesized at $1200{ }^{\circ} \mathrm{C}$ by solid-state reaction method. The DTA-TG results are indicating the structural modification of precursor materials after mechanical activation. Mechanical activation also helps in conversion of desired cordierite phase in higher quantity, which is confirmed by XRD study. So, milling helps to modify and rearrange the structure of precursor materials which attributes the lowering of sintering temperature of cordierite. Due to mechanical activation, the reactivity of mixtures increases and, consequently, cordierite is synthesized at $1200{ }^{\circ} \mathrm{C}$ without the aid of any additive. Physical properties of cordierite also improved with milling. Compact microstructure with better uniformity is found in higher-duration milled samples. This is due to formation of cordierite at lower temperatures for milled samples. Less compact and porous microstructures were formed in KAT00 and KAT30 samples due to presence of unreacted bigger size precursors particles in high percentage. KAT60 sample yields better properties compared to other milled samples. Although KAT45 sample properties are comparable with KAT60, it can be said that the tailor-made properties of cordierite can be achieved by changing the milling time with a same milling system.

\section{Acknowledgements}

The authors are grateful to the Director, CSIR-National Metallurgical Laboratory, Jamshedpur, India, for his kind permission to publish the paper. We would like to thank i-PSG team, CSIR-NML, for their support for this work.

\section{References}

Awano M, Takagi H and Kuwahara Y 1992 J. Am. Ceram. Soc. 752535

Bertran C A, da Silva N T and Thim G P 2000 J. Non-Cryst. Solids 273140

Boldyrev V V 1987 Thermochim. Acta 110303

Cristobal A A, Botta P M, Aglietti E F, Conconi M S, Bercoff P G and Porto Lopez J M 2011 Mater. Chem. Phys. 1301275

Ghitulica C, Andronescu E, Nicola O, Dicea A and Birsan M 2007 J. Eur. Ceram. Soc. 27711

Gokce H, Agaogullari D, Ovecoglu M L, Duman I and Boyraz T 2011 J. Eur. Ceram. Soc. 312741

Gonzalez-Velasco J R, Ferret R, Lopez-Fonseca R and Gutierrez-Ortiz M A 2005 Powder Tech. 15334

Ianos R, Lazau I and Pacurariu C 2009 J. Alloys Compd. 480 702

Kumar S, Singh K K and Ramachandrarao P 2000 J. Mater. Sci. Lett. 191263

Kumar S and Kumar R 2011 Ceram. Int. 37533

Marinkovic Stanojevic Z V, Romcevic N and Stojanovic B 2007 J. Eur. Ceram. Soc. 27903

Menchi A M and Scian A N 2005 Mater. Lett. 592664

Obradovic N, Dordevic N, Filipovic S, Nikolic N, Kosanovic D, Mitric M, Markovic S and Pavlovic V 2012 Powder Tech. 218157

Tamborenea S, Mazzoni A D and Aglietti E F 2004 Thermochim. Acta 411219

Temuujin J, Okadda K and MacKenzie K J D 1998 J. Eur. Ceram. Soc. 18831

Tkacova K, Heegn H and Stevulova N 1993 Int. J. Miner. Process. 4017

Yalamac E and Akkurt S 2006 Ceram. Int. 32825

Zhang Q, Lu J, Wang J and Saito F 2004 J. Mater. Sci. 395527 